Becerra, y también el interés de los trabajos que presentaba en cada lección, los que ya en esa temprana edad revelaban no sólo un talento excepcional, sino que una sorprendente capacidad para desarrollar sus ideas.

Su formación académica en la música se inició a los 10 años, a la que muy pronto agregó la de un inteligente autodidacta y pensador, capaz de descubrir por sí mismo los más ricos cauces de la técnica, el análisis y la composición. Llegó así a reunir un vasto y surtido catálogo de compositor, distinguirse como un profundo pensador en la docencia e investigación y, además, desempeñarse durante un tiempo en el espacio de la administración. Muchos de sus alumnos, activos hoy, se han destacado en la creación musical de Chile y tres de ellos han sido reconocidos con el Premio Nacional de Arte, Fernando García, Cirilo Vila y Miguel Letelier.

A los 25 años ya había escrito un número importante de obras que incluían música incidental para el teatro, composiciones para instrumentos solistas y conjuntos de cámara, un hermoso Concierto, para violín y orquesta, y el Cuarteto $\mathrm{N}^{\circ} 1$, para cuerdas, de sus siete obras de este género que, tal vez, representan su contribución más profunda a la música.

Sus viajes por Europa, pocos años después, le abrieron las puertas hacia nuevos horizontes en la didáctica de la composición, que formuló en sus escritos sobre "Crisis de la enseñanza de la composición en Occidente", ocho artículos publicados sucesivamente en los números 58 al 65 de la Revista Musical Chilena, de los años 1958 a 1959.

Produce un torrente de composiciones que parecen no excluir género alguno, desde su temprano neoclasicismo, pasando por el empleo de técnicas politonales y dodecafónicas, de fusiones con la tradición popular, procedimientos aleatorios hasta el empleo de los medios electroacústicos. En éstas y mucho más, se expresa dentro del espacio de una estética muy personal, afines a las motivaciones que le proveen sus ideas, en el momento histórico y sociopolítico en que le toca vivir.

La obra de Gustavo Becerra merece ser estudiada en profundidad y extensión, como lo han sido en Iberoamérica las de Heitor Villa-Lobos, Carlos Chávez, Silvestre Revueltas o Alberto Ginastera, por sus contribuciones a la música más allá de sus propias fronteras geográficas. La de Becerra es difícil conocerla en su totalidad dadas las dimensiones de su catálogo. Aun con esta limitación, me es posible destacar de épocas diferentes de su creación -además de su Concierto, para violín y orquesta-su Sonata $\mathrm{N}^{\circ} 2$, para guitarra; su Sonata $\mathrm{N}^{\circ} 5$ para violoncello y piano; sus Cuartetos de cuerda $\mathrm{N}^{\circ} 4$ y $\mathrm{N}^{\circ} 6$; sus Sinfonías $\mathrm{N}^{\circ} 1$ y $\mathrm{N}^{\circ}$ 2; su Concierto para guitarra y orquesta, de 1964; su Concierto, para percusiones y orquesta, que enclava un mensaje de paz; su oratorio Macchu Picchu, sobre el poema de Neruda, como obras del más original discurso y factura, y un par de sus atrayentes canciones en el estilo popular escritas para el conjunto Quilapayún.

Juan Orrego-Salas Universidad de Indiana, Bloomington, Estados Unidos jucar@ciswired.com

\title{
Recordando a Gustavo Becerra
}

Conocí a Gustavo Becerra en el Conservatorio, cuando estudiaba composición. Yo había escuchado algunas de sus sinfonías, su concierto para violín y una obra orquestal, cuyo nombre no recuerdo, pero que a menudo programaba la Orquesta Sinfónica de Chile cuando se trataba de difundir música nacional. También conocía sus cuartetos de cuerda, que eran muy apreciados por los melómanos de esa época. Era un hombre de baja estatura, pero enérgico, que hacía sus clases moviéndose incesantemente de un lado para otro y que daba muestras de gran sabiduría. Sus condiciones musicales excepcionales eran reconocidas por todos y hasta alentaban una suerte de mito en turno suyo. Recuerdo que si de pronto, en medio de la clase, sonaba una cañería, se escuchaba un ruido proveniente de la calle o el sonido de unas llaves que caían al suelo, inmediatamente Gustavo decía: "Do sostenido" o "Re bemol", y se dirigía al piano para comprobarlo. Siempre acertaba. Como profesor tenía un maravilloso poder para convencernos de que todo era fácil, de que todo era accesible, de que todo era cuestión de ponerse a trabajar. Ninguna idea musical de las que le llevábamos para 
analizar le parecía fuera de lugar. Todo lo recibía con la mayor naturalidad, desde esbozos de sonatas hiperrománticas hasta vanguardistas construcciones en las que se suponía que terminaban haciendo pedazos un violín a martillazos o tocando la trompeta con un fuelle de fundición. Su ecumenismo musical era tan extremo que resultaba a veces irritante, pero ello era más que todo debido a nuestros propios prejuicios. Con cualquier cosa se podía hacer música y no iba a ser él quien nos detuviera en nuestros ímpetus primerizos. Así, creo que Gustavo nos abrió de par en par las puertas de la música, nos hizo más libres y menos dogmáticos y nos ayudó a creer en nosotros mismos.

Lamentablemente, sus clases no duraron mucho, porque pronto fue nombrado Agregado Cultural de nuestra Embajada en Alemania y partió a Europa. Fue allí donde volvimos a encontrarnos en alguna de nuestras giras con el Quilapayún durante la época de la Unidad Popular. Cuando, finalmente, en septiembre de 1973 vino el Golpe, que nos sorprendió en Francia, una de las primeras personas a las que contactamos fue a él. Con Gustavo, con los Intis que se encontraban en Italia y con algunos otros amigos esparcidos por el mundo, formamos durante algunas semanas una red de información, a través de la cual compartíamos las noticias que nos llegaban desde Chile. Gustavo fue el centro de las primeras actividades de solidaridad que se organizaron en Alemania y que posteriormente dieron lugar al gran movimiento de solidaridad con Chile que se desarrolló en ese país. Durante esos años visitamos Alemania muchas veces y cada vez que pasábamos cerca de Oldenburg, Gustavo venía a saludarnos. Más de una vez cantamos en la propia Universidad donde él hacía clases y en la que fue siempre reconocido como una verdadera eminencia.

En alguno de esos encuentros surgió la idea de hacer algo juntos. Gustavo tenía pensado pasar un verano en España y cuando pasó por París hizo un alto en nuestra Tour de Colombes, donde lo recibimos a él y a su señora, Flor Auth, con el mismo cariño que siempre les manifestábamos. Una noche, justo antes de que partiera, le conté que hace tiempo teníamos el deseo de cantar una fuga y que no habíamos logrado hacer una. “¿Tienes algún texto de García Lorca?” -me preguntó interesado. Y agregó: “¡Tráemelo!”. Yo, felizmente, tenía en mi casa una pequeña recopilación de poemas del poeta andaluz y se la llevé. A la mañana siguiente, cuando nos estábamos despidiendo me pasó la partitura del Memento, obra que hemos cantado después en cientos de recitales. Algo parecido sucedió con la fuga Revolución, nacida de una conversación en su casa de Oldenburg, en la que comentábamos el tour de force que sería unir todas las canciones revolucionarias emblemáticas en una sola obra y utilizando una sola palabra. Al otro día, mientras tomábamos desayuno, me pasó la partitura de Revolución, fuga mucho más desarrollada, que felizmente grabamos rápidamente y que apareció muchos años después en Chile, incluida en el disco La vida contra la muerte. Le encantaban estos desafíos, que para él eran fáciles de realizar y disimulaba su satisfacción cuando le expresábamos nuestra admiración.

Era un hombre metódico hasta el extremo, rasgo que probablemente le venía de sus orígenes alemanes. Recuerdo que un día se dio un golpe en la cabeza con una ventana. Un golpe que parecía uno de tantos, pero que trajo sus consecuencias. Un día Gustavo se dio cuenta de que le costaba hacer operaciones aritméticas con ciertos números y llegó hasta identificar exactamente cuáles: a modo de ejemplo, desde el 547 hasta el 735. El médico insistía en que no se preocupara, pero finalmente accedió a hacerle exámenes más profundizados. Se descubrió que en su cerebro había un coágulo y que tenía que ser operado de urgencia. Así se hizo y felizmente el asunto no le trajo mayores consecuencias. Lo sorprendente fue su acuciosidad que lo llevó a determinar exactamente la gravedad de su mal.

Nuestros trabajos más ambiciosos fueron las cantatas América y Allende. En ambos casos, tuve que ir a visitarlo en Oldenburg con el objeto de precisar algunas cuestiones relativas a las posibilidades instrumentales y vocales del conjunto. Se trataba de obras escritas a medida y era necesario decidir de manera muy precisa quién iba a hacer cada cosa escrita. Así, pude entrar un poco en su intimidad y conocer su curioso modo de trabajar. Tenía tal dominio de la escritura musical, que escribía su obra mientras comentábamos las noticias de la televisión e intercambiábamos impresiones con su mujer sobre la situación chilena. Recuerdo que en el caso de Allende le sugerí agregar un piano en la parte final y él, sin dejar de conversar, escribió la partitura de punta a cabo en no más de media hora. Era prodigioso.

Lo divertido es que él sabía transmitir esta naturalidad de trato con la música escrita a todos los que nos acercábamos a su trabajo. Y eso fue exactamente lo que ocurrió cuando montamos América, en el invierno del año 1978, en que él nos llevó la partitura final a Colombes, y nosotros pudimos detener el ritmo desenfrenado de conciertos durante algunos días, para poder trabajar con él. El 
día del ensayo nos sentamos en círculo en la escena del teatro de Colombes, que el administrador amablemente nos había prestado, y él nos distribuyó las partes. Hasta ese momento no habíamos trabajado nunca con partituras, porque entre nosotros había quienes jamás habían hecho estudios de música. Yo iba a comenzar a explicarle esto para que Gustavo no se hiciera demasiadas ilusiones, pero él justo en ese momento dio la partida: "uno, dos, tres...". Lo que ocurrió fue un verdadero milagro. La música sonó de inmediato y el ensayo tuvo lugar de principio a fin como si todos hubiéramos sido avezados lectores de partituras. Montamos la obra en algunos días y hasta tuvimos tiempo para realizar un seminario sobre música chilena, al que invitamos a Los Jaivas y a todos los músicos nacionales que en ese momento se encontraban en París. A partir de ese momento, todo lo que hicimos fue con partituras escritas, lo que aumentó nuestras posibilidades expresivas. Lo que vino después no sería explicable sin este aporte que nos vino de Becerra, quien nos enseñó música con el mismo método que utilizan ciertos profesores de natación, que sin mayores explicaciones empujan a sus desconcertados alumnos directamente a las aguas profundas. Es verdad que en el caso nuestro el pataleo duró bastante poco, porque en muy breve plazo nuestra modalidad de trabajo cambió del cielo a la tierra. Además, aprendimos nuevos recursos musicales, como la politonalidad y la polirritmia, que nunca antes habíamos usado y que son desconocidas en la música popular.

Después vino Allende, con nuevas visitas nuestras a Oldenburg y nuevas venidas de Becerra a París. Lo montamos completo y hasta hicimos una grabación no profesional que por el momento se encuentra perdida. Es una obra bellísima, con un final impresionante. Nunca pudimos presentarla en público y se quedó sin grabar, porque en esa época no encontramos los medios para hacerlo. Golpeamos varias puertas, pero lamentablemente ninguna de ellas se abrió. He sabido que algunos jóvenes músicos se han interesado en ella y tal vez algún día se haga por fin una presentación de este trabajo. Sería un hermoso homenaje a dos hombres que desde sus vidas respectivas, uno desde la música y el otro desde la política, le entregaron un hermoso presente a Chile.

Una de las experiencias más cercanas la vivimos cuando ambos fuimos invitados al famoso Foro sobre la Cultura Chilena que tuvo lugar en Torum, Polonia, en mayo de 1979, el mismo donde conocí a Matta. Nos tocó compartir la habitación del hotel y como en ese preciso momento estaba ocurriendo el encontronazo que varios artistas empezamos a tener con los dirigentes comunistas, esa fue la feliz ocasión de discutir en profundidad nuestras ideas al respecto. Ambos compartíamos la crítica al estalinismo y ambos estábamos molestos con la actitud bastante doble de Volodia Teitelboim al respecto, que por un lado aparecía como el gestor de estas acciones culturales de solidaridad con Chile, pero por otro alentaba una línea dura dentro del Partido. El término de ese Foro fue muy desagradable para nosotros, porque a pesar de que le habíamos advertido a los organizadores que teníamos compromisos que nos obligaban a partir en un determinado día, ellos se desentendieron de nuestro problema y no hicieron las reservas necesarias. Nos enfrentamos con la burocracia polaca y finalmente logramos pasajes en tren hasta Berlín y desde ahí en avión hacia nuestros destinos finales. Tuvimos que hacer el viaje en tren, parados, porque no había asientos, lo que nos permitió tener largas horas de conversación sobre los problemas del "socialismo real" que, tal como se estaba presentando, no nos gustaba nada. Gustavo fue tan crítico de las dirigencias comunistas como nosotros, aunque sus posicionamientos no fueron muy difundidos. Su sentido de la libertad y su feliz experiencia en la Universidad de Oldenburg, que fue la institución que con mayor justicia reconoció sus méritos como profesor y como compositor, lo apartaban de todas estas visiones dogmáticas que tanto daño hicieron al movimiento popular chileno.

Después de todo esto, vino el término del exilio y poco nos encontramos. Sólo una vez, en la que él visitó Chile y en la que hablamos más de nuestras vidas que de nuestros proyectos musicales. En lo personal, fue un gran amigo, cercano, considerado, responsable y generoso. Como músico, creo que dejará una huella decisiva en la música chilena. Sus alumnos son todos grandes músicos de nuestra época, Sergio Ortega, Luis Advis, Cirilo Vila, Fernando García, Miguel Letelier, entre otros. Su catálogo de obras es impresionante y la mayor parte de ella nunca ha sido presentada en Chile. Ella incluye música sinfónica, conciertos para diversos instrumentos, oratorios, cantatas, música de cámara, canciones, obras electroacústicas y un sinfín de cosas más. Tal vez ahora con su muerte, las instituciones nacionales puedan hacerle justicia. Es cierto que muy joven, en 1971, se le otorgó el Premio Nacional de Arte, pero el verdadero reconocimiento de un compositor viene del conocimiento y de la difusión de su obra.

Lo veo mirándome fijamente detrás de sus anteojos, siempre serio, expresándome su preocupación por lo que pasaba en Chile, contándome alguna anécdota de sus relaciones con Neruda o 
hablándome del éxito de alguna de sus obras sin la menor arrogancia, como si se tratara de la cosa más natural del mundo. Parece que su enfermedad fue lenta y dolorosa. Sé que la llevó con la serenidad del hombre sabio que siempre él fue. Su historia se cruzó un momento con la nuestra y de ese cruce quedaron en nuestra alma destellos de luz que difícilmente se apagarán. Aunque nuestro arte haya agregado sólo un granito de arena a la grandeza de su obra, eso nos llenará siempre el corazón de orgullo, de alegría y de gratitud. Por eso es que con cariño y admiración hoy día lo despedimos.

Amigo Gustavo: como es el caso de todo gran artista, tu obra sobrevivirá a tu paso por la tierra. Esa es la única eternidad a la que aspirabas. Dejas nueva belleza en este mundo que abandonas. Fuiste profundamente solidario con los dolores de tu pueblo. Eso justifica ampliamente tu vida. Nosotros no te olvidaremos y esperamos que el resto de los chilenos tampoco. Hasta siempre.

Eduardo Carrasco Pirard Facultad de Filosofía y Humanidades Universidad de Chile, Chile educarr@manquehue.net 